\title{
The Influence of Cultural Differences between English and Chinese in Advertisement Translation and the Application of Domestication Principle
}

\author{
Qian Chen \\ Dept. of Foreign Language, Dezhou University, Dezhou, China
}

\begin{abstract}
Cultural differences are caused by different view on value, belief, different esthetic level, morality concepts and so on. The radical cultural differences between English and Chinese exert deep influence upon advertisement translation. Domestication principle is target culture oriented. And advertisement translation, being set at the reader's level of language and knowledge, is more likely to create equivalent effect, which makes it natural to apply domestication principle. What' more, the vocative function of advertisement requires the translators to strictly follow domestication principle in translation. The effectiveness of domestication principle in English and Chinese translation contributes a lot to successful cross-cultural communication.
\end{abstract}

Index Terms — advertisement translation, culture differences, domestication principle

\section{INTRODUCTION}

Advertisement, a widely used medium of communication in modern society, has direct effects on people's daily life in many aspects. Since it is an important driving force for the promotion of sales, it plays more and more critical role in enhancing the volume of domestic sales and international sales. Especially after China entering WTO, there are more opportunities of trade communication with other country around the world. In order to convey the producer's message to the target language consumers, advertisement translation is working as a bridge.

Advertisements generally contain specific meanings of a particular culture. Therefore, when they are translated to another language, knowledge of the different values and customs in different cultures is essential to the creation of effective and fruitful advertisements. So, translation of advertisements is, in a larger sense, a means of cross - cultural communication.

\section{Cultural DifFEREnCes between ENGLish ANd Chinese in AdVERTiSement Translation}

Cultural differences mean that due to different living environments, history, customs, etc people have different ideas in belief, value concepts, and modes of thinking, morality, etc. Advertisement is communication, not only a kind of which influence the economic activities, but also a kind of which influence people's life style and consumption patterns like invisible hands. Advertisement takes many forms, including language, pictures and music etc. Advertisement is the active constituent in the whole market, and the advertising language is full of abundant culture. All languages are the carriers of their respective cultures and they inevitably will be stamped with their own cultural characteristics. Advertisement language is the most important carrier of message, which conveys to us not only the information of the commodity, but also the unique ideas, values and other cultural messages. Without a good command of different cultures, it is difficult to realize a perfect communication between different languages. So a qualified translator should complete a communication between different cultures, making the translation follow the thinking habit of target language cultures, and to build a bridge for them. He or she should know clear about the basic culture differences which can make the translated version well understood and arouse the sympathetic purchasing action. The cultural differences can exert influence over advertisement creation and advertisement translation in various aspects.

\section{A. Different Cultural Values}

Obviously, cultural values have laid a strong foundation for people in different cultures. In advertising, it is strongly believed that the most effective advertisements are those that best express and affirm core cultural values. What advertisers and translators should do is to make the advertisements consistent with values of the targeted people. If not, they are likely to be rejected.

For example, respect for the old is a traditional virtue in the Chinese culture. There is an old saying in China“万善以孝为 先”(Filial respect for the old goes first in virtue). These ideas have been so deeply rooted in Chinese and regulate people's actions and behavior. In advertising, respect for the old is reflected by many Chinese brand names, such as“阿香婆”(Granny A'xiang),“老干妈”(old nominal mother), and“老干爹”(old nominal father). These brand names sound cordial to Chinese consumers and quite attractive. Similarly this virtue can be illustrated in the following advertising, for example,“正清制药, 关爱老人健康”(Zheng Qing Pharmaceutical Factory shows the utmost solicitude for the health of the elderly),“威力洗衣机, 
献给母亲的爱”(Weili Washing Machine is the love dedicating to Mothers). However, in the Western culture the word "old" is associated with the concepts of being "outdated" and "useless", and the words and phrases related to "age" are taboos. Since Western people are afraid of being old, such kind of advertisements is not often presented in English advertisement.

衣食住行，有龙则灵。(建设银行广告)

Your everyday life is very busy. But our Long Card can make it easy.

On one hand, "Long", Chinese people are easily able to associate it with cultural connotation of Chinese character “龙”.On the other hand, native speakers in English will regard "Long" as English word "long", which has deep implication that Construction Bank will offer long help for depositors to manage money matters, thus bringing out their long trust to savings.

\section{B. Different Traditions and Customs}

Every country has its own traditions and customs, which has formed by people's daily life. As we all know that when we learn a foreign language, it's very important to learn the relevant traditions and customs. So it is true in advertisement translation, the version must accord with the native traditions and customs. Here is a example. It is reported that the brand name of the Alarm Clocks made in Tianjin, has changed to "Golden Rooster" to supersede the original "Golden Cock". According to English tradition, "cock" is a taboo word, which can date to early $17^{\text {th }}$ century England and it is one of the many until Queen Victoria's coronation, whereby it became taboo to use it in her court. Misuse of the same word had appeared in trademark "Black Cock Pill" of traditional Chinese medicine Wu Ji Bai Feng Wan(乌鸡白风丸) Such pill is beneficial to women's health, but ladies in English countries may shrink back at the sight of the taboo word "cock". To get pragmatic equivalence in source and translated advertisement, it would be better to use "rooster" to replace "cock", which can both keep up original connotation and avoid such embarrassed failure as Jin Ji shoe polish factory does: “金鸡鞋油, 颜色有黑、棕、 白、红、黄等。”Golden Rooster shoe polish comes in black, brown, white, red, yellow, and so on.

Another example is concerned with "YONG FANG" Pearl Cream(永芳珍珠膏)which misuse the taboo word "fang". It is believed that“芳”in Chinese often evokes a beautiful image and association. According to Modern Chinese Dictionary, “芳” is defined as 芳香的(fragrant) and 美好的(happy or splendid). As a result, in Chinese language, positive qualities and attributes such as "beautiful", "fragrant", "glorious", etc. is imposed on the word“芳”. Take famous American brand name AVON as an example. In order to open up Chinese market for its cosmetics, the company endeavors to design a Chinese name with a favorable impression on Chinese ladies. Up to now it proved that “雅芳”'is deeply rooted in our country and its products are very popular with Chinese women. In English, however, the word "fang" which has same form with Chinese Pinyin “fang(芳)" is defined as: a long sharp tooth, as of a dog or a wolf; a snake's poisonous tooth. In such kind of negative, metaphoric models, audience can do nothing but escape from the product branded with Fang.

\section{Different Orientations: Customer Oriented vs. Product or Service Oriented}

Oriental people have different value and beliefs from occidental people. Most western countries adore individualism, freedom, equality and democracy, and they often use "you" attitude in their advertisements. So their advertisements can be regarded as customer-oriented because they take their own culture into full consideration. This conforms to the western style "Customer is God". Besides, they usually invite you to do something, but seldom give you a command. Because they believe that all people are equal and it is your own choice whether to accept the invitation or not, but never is of their business. They want you feel independent. However, in China, what we worship is collectivism, altruism and rank. Therefore, what we always use is "we" attitude and the tone of the advertisement is always imperative, asking you to do or not to do, and having made the choice for you. A good evidence for this can be the slogan that "Trust me and you will not miss it". Confronting with such a Chinese advertisement, many foreigners may not be free from making their own choice because they have just been put in such a passive environment.

Different orientation helps make different buying tendency. As we all know, western societies are more individualistic and thus more prone to strive for self-achievement, while the Chinese tend to be more collectivistic thus making constant reference to their peers. Reflected in buying beliefs, the westerners will choose products based on their specific needs while Chinese consumers tend to think that products or services favored by the majority are good ones. When the western people are going to purchase bags made by LOUIS VUITTON (LV) or shirts by GEORGIA ARMANI (GA), that is mostly because they think the quality and style match their needs. When the Chinese are to buy the same products, nine out of ten are influenced by others' opinion that people who buy and use those brands are rich, trendy and superior.

China is a society featuring collectivism and conformism, which leads to the individual's strong commitment and loyalty to his group and which poses strong influence on the creation of Chinese advertisements. Chinese advertisements stressing social norms and social acceptability will be favored while in western countries those featuring personal preferences and feelings will be well accepted.

Gillette Sensor: The only Razor that Senses and Adjusts to the Individual Needs of Your Face.

In the advertisements, the advertisers are fully aware of core values like individualism, self-respect, independence, and pursuit of individual benefits. In a society advocating individualism, such advertisements just hit the core value and meet consumers' pursuit of uniqueness and individualism Phrases like "especially for you" appear frequently in English advertisements.

On the contrary, traditionally as a collectivistic society, most Chinese consumers regard themselves in the context of a 
society and do not want to stray away from the society. Thus, they will choose the same products and brands chosen by other members of the group. So the advertiser makes full use of such conformity tradition and persuades all the consumers at the same time. The advertisements imply that it is natural to use things used by others.

Some examples:

(1).娃哈哈果奶:今天你喝了没有?

(Literal meaning: Have you drunk Wahaha Juice Milk today?)

(2)瑞奇服装:我们的牛仔服。

(Literal meaning: Ruiqi clothes---our jeans.)

So, if example (1) is translated as "Have you drunk Wahaha Juice Milk today", the first response of target consumers is the wonder why they should drink Wahaha Juice Milk at all with a repulsive feeling. Obviously, this first response is not desirable at all to advertisers. If example (2) is translated as "Ruiqi clothes---our jeans", the foreign consumers will feel uncomfortable of being stuck together with so many others of the same group of people, which run against the core value of individualism of a lot of western people. They will surely avoid such products likely to become uniforms.

\section{Different Political Background}

Because of different political systems and religious beliefs, misapplication of words in terms of policy, economy and culture with distinctive national features is another typical reason to cause miscommunication to English people who are unfamiliar with Chinese conditions. For instance,

“白熊牌”香兰素 Polar Bear Xiang Lan Essence

“大鹏牌”卷笔刀 ROC Sharpener

The phrase "Polar Bear" has particular connotation in international political language which refers to Russia, so consumers may think that the product was made in Russia. To avoid misunderstanding we would better change this English version to "White Bear" or something. As we know, in Chinese fairy tale "Da Peng" refers to the biggest bird with commendatory meaning. People can use the idiom“鹏程万里”to express blessing that someone will have a bright future. But it is possible for foreign customers to associate ROC with abbreviation of Republic of China. This translated brand name neither does good to establish good image of exports nor helps defend national dignity. If the products enter into the international markets, the English brand name should be changed like "Giant Eagle" or something to get pragmatic equivalence.

\section{E. Different Modes of Thinking: Hypotaxis vs. Parataxis}

Western and Oriental people have different modes of thinking: hypotaxis vs. parataxis. Western countries emphasize hypotaxis, and there is a strong logic relation among their language marks, while Chinese emphasizes parataxis that meaning of words connects sentences. In English advertisements, different parts of the sentences are always connected by many conjunctions and propositions, which do not have practical meanings. It pays much attention to the attributive, rhetorical, equal and contrastive relations between the sentences through the meanings of words. So, from this point, we say that English is more complicated than Chinese. Translators should either add or omit some words to make readers with different native tongues feel comfortable and to minimize the strangeness brought by a foreign language.

Different modes of thinking make people express themselves in different ways. The obvious contrast is coming straight to the point and talking in a roundabout way. Foreigners like to speak out their ideas at the beginning of their statement, and then give their detailed description. But we Chinese people are not used to stating the ideas too directly. Instead, we speak more tactfully and may use more euphemism. We are accustomed to put less important things first, and then talk step by step, with the conclusion given at the end of the paragraph. So the focus is put at the end of an advertisement. But this does not conform to foreigners' expression habit. So during advertisement translation, translators must pay attention to the difference and try to make the translation accords with the expression habits of target language readers.

From the above analysis we can see that advertising is the products of culture, and is deeply rooted in the whole national culture. In designing and translating advertisements, advertisers or translators may easily neglect the customs, conventions, religions in different countries and nationalities, etc. The values, life style of a nation, religion, morals, and ethic standards have to be seriously considered in the translation of advertisement. The application of appropriate translation methods is quite essential in order to make the advertisement well understood and accepted by target language customers.

\section{The NeCESSITY TO APPLY DOMESTICATION PRINCIPLE}

Domestication is a translation strategy which is target culture oriented, which came out in the old Rome, but has been widely used in the practice for a long time. It uses target or some other language that are similar with target language to translate works, articles, and papers, which are written in another different language. It uses transparent and fluent style, and follows the thinking habit of target language readers to the minimum level, also to make the translation fluent, folk and easy to be understood, with the pursuit of the accomplishment of communication between different cultures. (Guo, 2000) The application of domestication principle in English and Chinese translation is in accordance with the requirement of translation, in which the dynamic equivalent effect should be taken into consideration. In The Theory and Practice of the Translation Nida proposed the theory of Dynamic Equivalent Effect, which advocates producing the same effect on the readership of the original during the translation. (Nida, 2001) His theory has been the criterion by which the effectiveness, and therefore the value of the translation of advertisement are to be assessed. 
Advertisement translation as a communicative translation, being set at the reader's level of language and knowledge, is more likely to create equivalent effect. Owing to their communication style, English advertisements are going to be settled in the Chinese background after being translated, and vice verse. But one same purpose is that the effects created among the source language readers and the target language readers are the same. Different from literature translation, the essence of the source language culture is not as important in the communicative translation. Therefore, only if we can successfully obtain the closest effect in two languages, can the translation be called reasonable and whether it keeps the same flavor or culture seems not at all important. That is the main reason why we should adopt the domestication principle.

Then the vocative function of advertisement requires the translators to strictly follow domestication principle in translation. Advertising spreads related information of services and ideas to consumers. It has the function of communication. People rely on advertising to obtain product and service information, then further decide whether to take buying actions or not. Thus, it has the informative, vocative and persuasive functions. The core of the vocative function is the readership, the addressee. It is used to call upon the readership to act, think or feel, in fact to react in the way intended by the advertisement. It has two factors. The first one is that the relationship between the writer and the readership is realized in various types of socially or personally determined grammatical relations or form of address, playing a great role in determining the tone of advertisement; the second one is that the advertisement must be translated in a language that is immediately comprehensible to the readership. From these two factors we can conclude that the vocative function of advertisement requires the translators to strictly follow domestication principle in translation.

If we are guided by domestication principle, we are setting the advertisements in the target language and culture, considering their customs, values, modes of thinking, etc, to deliver the original meaning of the advertisement. Therefore, the target customers' reaction can be judged from their own backgrounds, which tend to be the same or at least the closest to the source language customers. So the application of domestication principle is very helpful to achieve the dynamic equivalent effect.

\section{APPROPRIATE APPROACHES OF APPLYING DOMESTICATION PRINCIPLE}

In order to minimize the cultural strangeness for target language readers, domestication is suggested in the translation in order to get the expected effect, because it has full consideration of target language readers' acquisitive ability and esthetic orientation. The application of domestication in advertisement translation is feasible and helpful. Translators can benefit from this strategy to play well the role of decoder and mediator, so that the message in the advertisement can be transferred to the target language readers correctly and effectively. In order to make an appropriate application, several approaches are available as follows:

\section{A. Omission}

Omission generally refers to omitting some articles, prepositions, adverbs, pronouns, etc. when we do translation from English to Chinese. Those omitted are necessary in an English text that emphasizes hypotaxis, but they have no practical meanings. While we are translating Chinese into English, we also should omit some words, and what we omit are words that have strong Chinese characteristics. These words are just used to reinforce the focus or for the sake of parallelism or the balance of the whole sentence, so as to strengthen the persuasive power of advertisement. So, we do omitting to make the translation conform to target language readers' thinking or expressive habit, and to make the translation easy to be accepted. For example:

我公司以“质量第一，顾客至上”的经营宗旨，集潮州工艺之精华，博采众家之长，独领风骚，深受国内外客户的 好评，并已在世界上建立了良好的贸易关系网。竭诚欢迎各界同仁光临垂询，友好合作，共同发展陶瓷业。

Adhering to the principle of quality and client first, our commodities are of high quality and enjoy a good reputation among the users both at home and aboard. We sincerely welcome orders and cooperation.

Comparing with the original, some words have been omitted in the translation, such as “集潮州工艺之精华，博采众家之 长，独领风骚”, just be translated into “our commodities are of high quality”, which is simple enough. “并已在世界上建立 了良好的贸易关系网” has totally been omitted. In Chinese, there are so many rhetorical words, such as fours words or six words paraphrases, which have strong power. But in English, there is no equivalent for them, so omission is necessary here. Although the parallelism in the original makes force, it will be tiresome and will enervate for English readers. Another word “风骚” and the last sentence “共同发展陶瓷业” have strong Chinese characteristics. This is a reflection of collectivism. But foreigners adore individualism. This is contrary to our Chinese habit "welcome to cooperate with us" and so on. So omission is adopted here to make foreign readers easy to understand the meaning of the advertisement and feel comfortable to get the general but essential meaning of the original. Considering their own value concepts can make it easier for them to accept the advertisement at last.

\section{B. Addition}

Addition means that while translating, translators should add some words to make the translation consecutive, fluent and perfect. It is opposite to omission. The added parts contain the omitted contents of the original, the latent means of the text, some rhetorical words such as adjectives or adverbs, to make the translation affluent, and to suit with target language readers' taste. For example:

7 UP 
The Uncola

Made to go the cola one better

Fresh, clean, crisp

Never too sweet

No after taste

Everything a cola's got and more

7 UP...The Uncola

The Un and only

七喜

大众的可乐,

它是众可乐中的佼佼者,

它新鲜, 干净, 清爽。

甘甜可口，

意犹未尽。

它博取众家之长,

七喜, 大众的可乐,

它是你唯一的最佳选择。

In the translation, four pronouns of “它” are added, which gives a definite indication of the drink-7 UP. "It" emphasizes that it is this drink that brings us those pleasant feelings. Its name — 7 UP has been put at the most important position, which can give the readers an obvious guidance, leading them to come to the drink, and have a taste of it. Besides, there are some other words added to the translation, such as the two “最”, to make the translation fluent and folk. In this way addition helps extrude the focus of the advertisement_ — the product, which suits well people's way of acceptance.

\section{Inversion}

As being discussed above, English and Chinese have different orientations and ways of expression, so translators should flexibly follow their separate habits and change the sentence order or adjust the focus. So inversion is necessary. And here are some examples:

We have hidden a garden full of vegetables where you'd expect. In a pie.

在你意想不到的地方, 我们珍藏了满园的蔬菜, 那是在小小的馅饼里。

Here the translator put the meaning of "where you would expect" at the beginning of the sentence, with the purpose of emphasizing the surprise. So at the first sight of this advertisement, people may want to know what the place is exactly in. This meets Chinese people's curiosity, and they get great pleasure from it. Because of this strong attraction, they come to the restaurant, sit down and have a good share of this delicious pie.

Another good example for the use of inversion is an advertisement of electronic warmer.

外面冰冻三尺, 屋内春意融融。

Better cozy is here than cold there.

In this advertisement, the translator applies the structure "better...than..." to the translation, which conforms to the English thinking habit. Through the use of this structure, the comparative effect is achieved and the readers are given good visual sense. They may then form in their mind a clear understanding of this product, which helps a lot in their decision making.

\section{Substitution}

Substitution is to use some target language words to substitute the unfamiliar words so that we can minimize the strangeness brought by the original to the minimum level. For example:

Revlon

露华浓

For Chinese, the first impression of this translation might be memory of the popular poem written by Li Bai, a famous poet in the Tang dynasty. It writes that “云想衣裳花想容，春风拂褴露华浓。若非群玉山头见，会向瑶台月下逢。” which describes a well known ancient beauty_—Yang Yuhuan's attraction. In this translation homophony is adopted_—_Revlon” and "Lu Hua Nong", to give readers an imagination of her beauty. Then a hint is given to the readers that by using this kind of cosmetics, they will own the appearance as attractive as Yang Yuhuan. So in the translation, the domestication principle is adopted due to Chinese people's familiarity of Li Bai's poem, and it is also a good illustration of substitution.

\section{E. Conversion}

Conversion usually takes words and sentence as its object. It contains adjustment of the relation between words and sentences. Translators may change nouns into verbs or adjectives, and change preposition or adverbs into verbs during translation. Sometimes, conversion from passive to active voice is also necessary. Another case is to change the sentence pattern when necessary, making the change between the imperative, exclamatory, question and so on. For example:

The choice is yours.

The honor is mine.(某大型商场牌角广告) 


\section{带走你的选择，留下你的荣耀。}

Here the two nouns “choice and honor” are changed into two verbs “带走” and “留下”, which makes the translation polite and active enough to match the customers' psychological needs. This translation has given the customers a message of invitation and respect. Comparing with the translation “选择是你的, 荣耀是我的”,will the customers not feel a little bit uneasy and a sense of distance and indifference between themselves and the storeowner! The latter translation has created a gap, while the former one has been a reflection of freedom and democracy. The customers are invited but never commanded. Since the advertisement is designed to please the customers, translators should think what the customers may think and feel what they may feel, in order to guide the advertisement to success.

\section{CONCLUSION}

With the development of world integration, the earth is becoming a global village. China's entering WTO has brought the country even more closely to the world market. Advertisement translation is working as a bridge to connect the producer's message and the target language consumers.

Different languages have different culture backgrounds. Without a good command of different cultures, it's impossible to realize a perfect communication between different languages. Cultural differences are caused by different view on value, belief, esthetics, morality concepts and so on. Advertisement translation requires translators to be fully aware of the differences, get rid of culture influence to fit target language, know well the consumers' psychology and consumers' behavior, master target language usages and cultural specifics.

The cultural differences between English and Chinese calls for the application of domestication principle, which is necessary and beneficial. With the adoption of domestication principle, translators could make the translation follow the thinking habit of target language cultures and conform to foreign readers' specific mode of thinking. The effectiveness of domestication principle in English and Chinese translation contributes a lot to successful cross-cultural communication.

\section{REFERENCES}

[1] Guo zhuzhang \& li qingsheng. (2000). A Course on English and Chinese Translation. Wuhan: Wuhan University Press.

[2] Kotler.P\& G Armstrong. (2001). Principles of Marketing. London: Prentice Hall Press.

[3] Kramsch, Claire. (2003). Language and Culture. Shanghai: Shanghai Foreign Language Education Press.

[4] Marshall, S. (1987). Intercultural Communication: A perceptual approach. London: Prentice Hall Press.

[5] Nemetz, Gail. (1988). Cross Cultural Understanding. San Francisco: Prentice Hall International Ltd.

[6] Newmark, P. (2001). Approaches to Translation. Shanghai: Shanghai Foreign Language Education Press.

[7] Nida, E. A. (2001). The Theory and Practice of the Translation. Shanghai: Shanghai Foreign Language Education Press.

[8] Nida, E. A. (1993). Language, Culture and Translating. Shanghai: Shanghai Foreign Language Education Press.

[9] Nord, C. (2001). Translating As a Purposeful Activity. Shanghai: Shanghai Foreign Language Education Press.

[10] Porter, R. E \& Samovar, L. A. (2002). Communication between Cultures. Beijing : Foreign Language Teaching and Research Press.

[11] Rutledge, M. B. (2007). Encyclopedia of Translation Studies. Shanghai: Shanghai Foreign Language Education Press.

[12] Sandra E. Moriary. (1986). Creative Advertising. London: Cambridge University Press.

[13] Thomas, J. (1983). Cross-cultural Pragmatic Failure in Applied Linguistics. London: Oxford University Press.

[14] Tytler, A. (2007). Essays on the Principles of Translation. Beijing: Foreign Language Teaching and Research Press.

[15] William, S. (1987). Foundations of Intercultural Communication. Shanghai: Shanghai Foreign Language Education Press.

Qian Chen was born in Leling, China in 1974. She received her M.A. Degree in English language teaching from He Bei Normal University, China in 2002.

She is currently an associate professor in English Department, De Zhou College, Dezhou, China. Her research interests include English language teaching and American literature. 